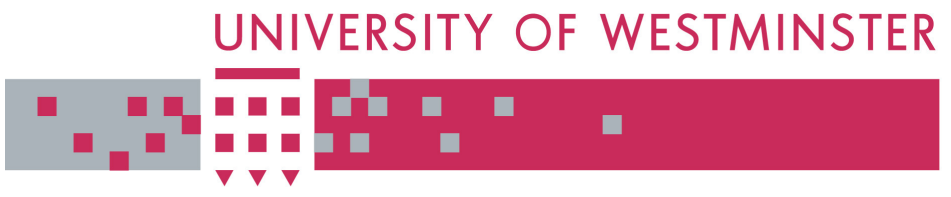

\title{
WestminsterResearch
}

http://www.wmin.ac.uk/westminsterresearch

\section{A colour normalization method for giemsa-stained blood cell images.}

\section{F. Boray Tek ${ }^{1}$}

Andrew G. Dempster ${ }^{2}$

Izzet Kale ${ }^{1,3}$

${ }^{1}$ School of Informatics, University of Westminster

${ }^{2}$ School of Surveying and Spatial Inf. Sys., University of New South Wales, Sydney, Australia

${ }^{3}$ Applied DSP and VLSI Research Centre, Eastern Mediterranean University

Copyright ( ) [2006] IEEE. Reprinted from the proceedings of the 2006 IEEE 14th Signal Processing and Communications Applications.

This material is posted here with permission of the IEEE. Such permission of the IEEE does not in any way imply IEEE endorsement of any of the University of Westminster's products or services. Internal or personal use of this material is permitted. However, permission to reprint/republish this material for advertising or promotional purposes or for creating new collective works for resale or redistribution must be obtained from the IEEE by writing to pubs-permissions@ieee.org. By choosing to view this document, you agree to all provisions of the copyright laws protecting it.

The WestminsterResearch online digital archive at the University of Westminster aims to make the research output of the University available to a wider audience. Copyright and Moral Rights remain with the authors and/or copyright owners.

Users are permitted to download and/or print one copy for non-commercial private study or research. Further distribution and any use of material from within this archive for profit-making enterprises or for commercial gain is strictly forbidden.

Whilst further distribution of specific materials from within this archive is forbidden, you may freely distribute the URL of the University of Westminster Eprints (http://www.wmin.ac.uk/westminsterresearch).

In case of abuse or copyright appearing without permission e-mail wattsn@wmin.ac.uk. 


\title{
Giemsa ile Lekelenmiş Kan Hücresi İmgeleri için Bir Renk Düzgeleme Yöntemi A Colour Normalization Method for Giemsa-Stained Blood Cell Images
}

\author{
F. Boray Tek ${ }^{1}$, Andrew G. Dempster ${ }^{2}$, Izzet Kale ${ }^{1,3}$ \\ ${ }^{1}$ Applied DSP and VLSI Research Group, University of Westminster, London, UK \\ ${ }^{2}$ School of Surveying and Spatial Inf. Sys., University of New South Wales, Sydney, Australia \\ ${ }^{3}$ Applied DSP and VLSI Research Centre, Doğu Akdeniz Üniversitesi, Gazimagusa, KKTC \\ boraytek@yahoo.co.uk, a.dempster@unsw.edu.au, kalei@westminster.ac.uk
}

\begin{abstract}
Özetçe
Bu bildiride, Giemsa ile lekelenmiş kan hïcre imgelerinin renk düzgelemesi için yeni bir yöntem sunulmaktadır. Önerilen yöntemde imge ön (hücreler vb) ve arka plan (plazma) olarak iki bölgeye ayrılmakta, daha sonra düzgeleme işlemi bu iki bölgeye farklı şekilde uygulanmaktadır. Ön ve arka plan, matematiksel morfoloji yardımılla kaba bir şekilde kestirilmekte ve ayırma işlemi bu bölgelerin histogramına bağlı olarak yapılmaktadır. Ayrılmış olan arka plan bölgesi kullanılarak, genel aydınlanmadan bağımsız bir imge elde edilmektedir. Buna ek olarak, ön plan imgesi referans olarak belirlenmiş imgelere göre dönüştürülüp, düzgeleme işlemi tamamlanmaktadır. Önerilen yöntem bir çok imge üzerinde denenmiş ve başarılı bulınmuştur.
\end{abstract}

\begin{abstract}
This paper presents a novel method for the colour normalization of Giemsa-stained peripheral blood cell images. The normalization is applied separately to the foreground and background regions. A rough estimation of the foreground-background regions is done by mathematical morphology and followed by a refined segmentation using histograms of these regions. Then an illumination independent response is calculated using the background region. The normalization is completed by transforming the foreground region according to a reference set. The proposed method has been tested on many images and has been found successful.
\end{abstract}

\section{Giriş}

Bu çalışmada sunulan imge düzgeleme yöntemi, sıtma hastalığının bilgisayarla tanısı amacıyla geliştirilmekte olan bir sistemde imgelerin önişlenmesinde kullanılmak üzere geliştirilmiştir. Yöntemin genel olarak amacı giriş imgesinin bir referans imge renk karakteristiğine uyarak bilgisayarla parazit sınıflandırma ve sayma işleminin doğruluğunu arttırmasıdır. Giemsa lekeleme sitma gibi çevrimsel kan parazitlerinin yol açtığı hastalıkların mikroskop ile tanısında örnekteki parazitik elemanları belirginleştirmek için kullanılan yaygın bir yöntemdir [1]. Bu işlem parazitik elemanları ve örnek içerisinde yer alan diğer çekirdekli yapıları (akyuvarlar çekirdekli, alyuvarlar çekirdeksizdir) lekeleyerek belirginleştir ve mikroskop altında incelendiginde parazetemi (parazitli alyuvar, sağ lıklı alyuvar sayıs1 oran1) kestirimine olanak sağlar. Bilgisayarla tanı söz konusu olduğunda, hazırlanmış bir örnek yaygın kullanılan bir ışık mikroskobu ve sayısal bir kamera ile görüntülenebilmektedir. Görüntülenen imgelerde tanıyı etkileyebilecek bir çok durum bulunmaktadır. Örnek hazırlanmasında oluşabilecek durumlar farklı Giemsa yoğunlukları, homojen olmayan bir şekilde lekeleme, daha uzun veya daha kısa tatbik süreleri olarak sıralanabilir. Görüntü alma sisteminde ise mikroskop 1şı ̆̆1, diyafram ayarları, kullanılan kromatik süzgeçler veya kamera ayarları (beyaz denge, diyafram, enstane hızı gibi) gözlenen renklerin farklı olmasına yol açmaktadır.

$\mathrm{Bu}$ çalışmada kan örneklerinin hazırlanması ve görüntülenmesi sırasında yer alan işlemlerde herhangi bir kontrolün olmadığı kabul edilmiştir ve renklerdeki farklılıklar kaynaklarından bağımsız bir şekilde giderilmeye çalışılmaktadır. Görüntüleme sonrasında elde edilen sonuç imge, bir referansta (istenilen özelliklerde herhangi bir imge veya imge kümesi) gözlenen renk karakteristiğine uyması için bir dönüşüme tabi tutulmaktadır. Literatürde görüntülenen nesnelerin özelliklerinden bağımsız olarak geliştirilmiş bir çok renk dïzgeleme yöntemi bulunmaktadır [2]. Bunlardan en basiti gri-dünya yöntemidir. Bu yöntemde farklı imgelerde gözlenen renklerin gri seviyesinin sabit olacağı kabul edilmekte ve referans griye oranla düzgelenebilmektedir. Grinin seçimi sabit evrensel bir gri (örneğin KYM:kırmızı, yeşil ve mavi kanalların orta değeri) olabileceği gibi imgelerin bir istastiğide olabilir. Veya görïntii alma sistemi mevcutsa beyaz bir görüntülenebilir alan kullanılarak (kırmızı-yeşil-mavi enüst değerleri gözlendiğinde) gri sisteme göre tespit edilebilir. Genel sıradan bir resim için, gri dünya algoritması aynı amaçla geliştirilmiş yöntemlere göre daha düşük başarı sağlarken [2], ön ve arka plan olarak bölütlenmiş bir imge için daha başarılı olabilmektedir [3]. Bu çalışmada söz konusu olan imgeleri ön (hücreler vb.) ve arka (plazma) plan olarak bölütleyebilmekte ve buna ek olarak plazmanın doğal koşullarda olarak renksiz bir s1v1 olduğu kabülünden yararlanabilmekteyiz [1]. Böylece giriş imgesinde yer alan arka plan ortalamaların kullanarak tüm imge üzerindeki aydınlanma etkilerini azaltabilmekte, 
daha sonra sadece ön plan1, bir referansta yer alan ön plan karakteristiğine göre dönüştürebilmekteyiz.

$\mathrm{Bu}$ çalışmada ön ve arka plan bölütlemesi için kullanılan yöntem Rao [4] tarafından geliştirilmiş ve kan hücresi imgelerinin bölütlenmesinde başarı ile kullanılmıștır. Yöntem alyuvarların sabit (çok yakın) alanlara sahip olduğu kabulünden yararlanarak gri düzey görüntüler ïzerinde matematiksel morfoloji (biçimbilim) algoritmaları kullanarak bölütleme yapmaktadır. Bu bildiride Yöntem bölümün ilk kısmında bu işlem tanıtılmaktadır, ikinci kısmında ise bu bölütlemeye dayalı düzgeleme yöntemi sunulmaktadır. Daha sonraki bölümlerde deneysel sonuçlar ve vargılar bulunmaktadır.

\section{Yöntem}

Önerilen yöntem ön arka plan bölütlemesi ve renk düzgelemesi olmak üzere iki alt kısımda incelenebilir.

\section{1. Ön ve Arka Plan Bölütlemesi}

Örgü spektrumu veya diğer bir deyişle granulometri, imge işlenmeden önce nesnelerin boyutu hakkında ön bilgi edinmek için etkin bir araçtır [5], [6]. Breen ve Jones [7] granulometrinin öznitelik açma (attribute opening) işlemleri ile ilişkili genel bir tanımlamasını yapmış ve öznitelik granulometrisi için verimli bir algoritma geliştirmiştir. Genelleştirilmiş granulometride kullanılabilecek öznitelikler genişlik, alan gibi artan kriterler olabileceği gibi öznitelik inceltme (attribute thinning) ile kullanılabilecek (dışmerkezlik, derlitopluluk vb) artmayan kriterler de olabilir. Alan granulometrisi kan hücrelerinin yarıçaplanının kestirimi için bazı çalışmalarda kullanılmıştır [8] [9]. Gri düzey bir imge için $I_{g}$, alan granulometrisi ardışık alan açma işlemleri arasındaki diferansiyel kütle hesaplanarak bulunabilmektedir:

$$
f(k)=\sum \gamma_{k}^{a}\left(I_{g}\right)-\sum \gamma_{k-1}^{a}\left(I_{g}\right) \quad k>(k-1) \in R
$$

, $\left(\gamma_{k}^{a}\right), \mathrm{k}$ alanı gösterdiğinde $k$ değeri ile alan açma işlemidir.

Kan hücreleri mikroskoptan alınan bir imgede plazmaya göre daha koyu, eğrili ve dışbükey bir görünümdedir. Böyle bir imgenin $I_{g}$ (gri düzey) tersi üzerinde alan granulometrisi hesaplandığında hücre alanı $(A)$ ve sözde yarıçapı için bir kestirim yap1labilmektedir. Şekil 1(b), Şekil 1(a) daki giriş imgesinin gri düzey tersi üzerinde hesaplanmış olan alan granulometrisini artan alan indisine göstermektedir. Kan hücrelerinin imgede en yoğun sınıf olduğu varsayımı ile granulometri grafiği üzerinde yer alan en yüksek tepe değerinin kan hücrelerinin alanını gösterdiği kabul edilmektedir. Diğer tepe değerleri dokunan kan hücreleri, beyaz kan hücreleri (kırmızı kan hücrelerinden daha büyüktür) olduğu deneysel olarak gözlenmiştir. Grafikte görülen en yüksek tepe değerine ait dizin alan $\left(A_{1}\right)$ sonraki işlemlerde hücrelerin veya daha genelleştirirsek ön planın alan kestirimi olarak kullanılmaktadır.

Hücreleri temsil eden bir alan kestirimi bulunduğunda alan açma işlevi kullamılarak ön planı arka plandan ayıran kaba bir ikili gösterim elde edilebilmektedir:

$$
B=\left(\gamma_{\left(A_{1}-\epsilon\right)}^{a}\left(I_{g}\right)-\gamma_{\left(A_{1}+\epsilon\right)}^{a}\left(I_{g}\right)\right)>0,
$$

alan açma işlevi $A_{1} \pm \epsilon$ değeri ile kestirilen hücre alanından biraz fazla ve daha az alan açma gerçekleștirmekte, bu iki açma

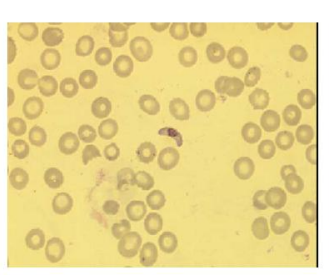

(a)

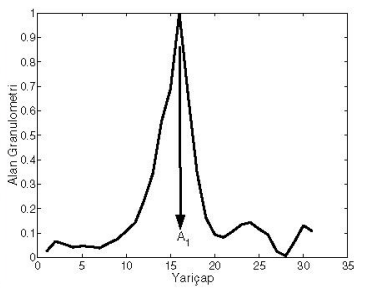

(b)
Şekil 1: (a) Giriş imgesi ( $I$ ), (b) ve imgenin gri düzey tersinden hesaplanan alan granulometrisi ve tepe alan indisi $A_{1}$.

arasında kalan nesneler kaba bir şekilde hücreleri belirlemektedir. Elde edilen ikili gösterim $(B)$ imge üzerinde $\left(I_{g}\right)$ bir maske olarak kullanıldıgında ön ve arka plana ait iki ayrı imge ve bu imgelere ait iki ayrı sıklık dağılımı elde edilebilmektedir. Genel bir tek kanal imgenin sıklık dağılımını $H_{I} \hat{=}\|I\|$ ile gösterirsek ön ve arka plan imge kanallarına ait iki ayrı düzgelenmiş sıklık dağılımı şu sekilde ifade edilebilir:

$$
\begin{array}{ll}
I o=I_{g} * B & I a=I_{g} * \dot{B} \\
h_{I o} \hat{=} \frac{\|I o\|}{\sum(B)} & h_{I a} \hat{=} \frac{\|I a\|}{\sum(\dot{B})}
\end{array}
$$

$(B), B$ olmayan yani arka plan maskesini göstermektedir, $h_{I o}$ veya $h_{I a}$ sirasıyla ön ve arka plan için toplam piksel sayısına bölünerek düzgeleştirilmiş sıklık dağılımlarını temsil etmektedir. Şekil 2 de, daha önce Şekil 1(a) da gösterilen imgeden hesaplanmış ön plan maskesi $B$ ve surasıyla tümüne $h_{I}$, ön $h_{I} O$ ve arka planlara $h_{I} a$ att düzgelenmiş dağ 1 lımlar görülmektedir. Şekilde görüldügü gibi kaba ikili gösterim yardımıyla hesaplanan ve kendi içerisinde düzgeleştirilen $\mathrm{s} 1 \mathrm{kl} ı \mathrm{k}$ dağılımlarında ön ve arka plana ait tepe noktaları belirgin bir şekilde ayrılmıştır. İmgenin tümüne ait iyileştirilmiş sıklık dağılımı iki ayrı sıklık dağılımının birleştirilmesi

$$
h_{e}=\operatorname{argmax}\left(h_{I o}, h_{I a}\right)
$$

ile elde edilebilmektedir. Bu özellik sadece gösterim için kullanılmaktadır, bu çalışmada kullanılmamaktadır. Gerektiğ hallerde dağ1lımlar birleştirmeden önce süzgeçlenebilir, iyileştirilmiş sıklık dağılımı Şekil 2(d) de görülmektedir.

Ön ve arka plana ait tepe renk değerleri $p_{o}, p_{a}$ siklik dağılımları üzerinde hesaplandığında eşikleme amacıyla kullanılabilmektedir. Eșikleme için iki değere dayalı morfolojik eşikleme yöntemi tercih edilmiştir. Bu yöntem gri düzey bir imge $I$ şu şekilde ifade edilir [10].

$$
T T\left[t_{1} \leq t_{2} \leq t_{3} \leq t_{4}\right]\left(I_{g}\right)=R_{T_{\left[t_{1}, t_{4}\right]}^{\delta}\left(I_{g}\right)}^{\delta}\left[T_{\left[t_{2}, t_{3}\right]}\left(I_{g}\right)\right],
$$

$T_{\left[t_{a}, t_{b}\right]}(I) \quad t_{a}$ ve $t_{b}$ değerleri arasında eşiklemeyi gösterirken, $R_{P}^{\delta}[Q]$ : P'den Q'ya morfolojik sonsuz geriçatılma işlevini göstermekttedir. $T T\left[t_{1} \leq t_{2} \leq t_{3} \leq t_{4}\right](I)$ iki değere dayalı eşiklemedir ve sonucu ikili bir gösterimdir. Bu işlemi $t_{1}, t_{2}=0, t_{3}=p_{o}, t_{4}=p_{a}$ için hesapladığımzda giriş imgesine ait rafine bir ön plan maskesi elde edilir. Bu maske izleyen bölümde ön ve arka plan renkli imgesini belirlemek için kullanılmaktadır. 


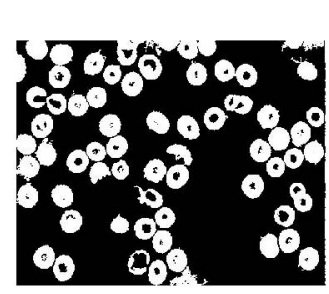

(a)

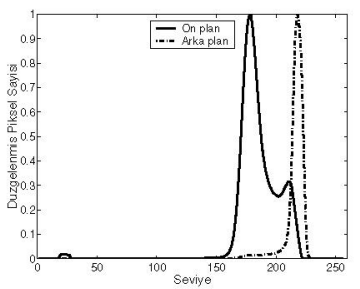

(c)

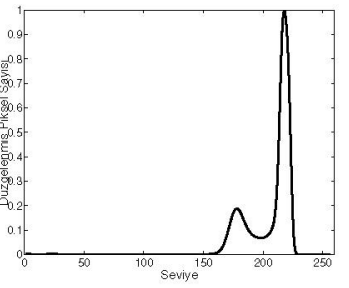

(b)

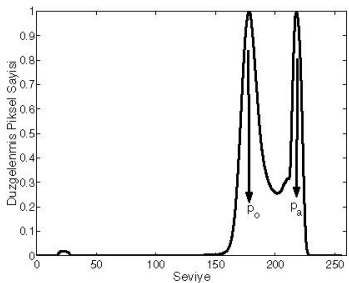

(d)
Şekil 2: (a) Ön plan maskesi $(B)$, (b) giriş gri düzey imgesinin sıklık dağ1lımı (c) ön $h_{I o}$ ve arka plan imgelerinin s1klık dağ 1 ımı $h_{I a}$ (d) birleştirilmiş yeni sıklık dağılımı $h_{e}$

\subsection{Renk Düzgelemesi}

Literatürde aydınlanma farklılıkları için değişik modeller bulunmaktadır [2]. "Köşegen model" diğer modeller arasında en basitidir ve bir çok algoritmada kullanılmaktadır. Bu modelde bilinmeyen bir aydinlanmaya tepkiden $\left(\mathbf{p}^{u}=\right.$ $\left.\left(p_{1}^{u}, p_{2}^{u}, p_{3}^{u}\right)\right)$ bilinen bir aydınlamaya tepki $\left(\mathbf{p}^{c}=\left(p_{1}^{c}, p_{2}^{c}, p_{3}^{c}\right)\right)$ dönüşümün $3 x 3$ köşegen bir matris $M$ ile $\left(\mathbf{p}^{u}=\mathbf{M p}^{c}\right)$ şeklinde olduğu kabul edilmektedir. Köşegen modeli kullanarak geliştirilmiş bir çok farklı imge renk düzgeleştirme, aydınlatıcı kestirimi yöntemi bulunmakla birlikte gri dünya algoritması bunların içerisinde en basitidir ve suradan imgelerde kullanıldığında diğerlerine göre çok başarılı olamamaktadır [2]. Ancak bu çalışmada kullanılan imgeler, ön-arka plan şeklinde ayr1labildiği ve gözlenmesi beklenen nesneler hep aynı sınıfta olduğundan, gri dünya algoritması verimli bir şekilde çalışabilmektedir. Bu algoritmada, aydınlatmadan bağımsız piksel tepkisi kabul edilen gri değerine oranlanarak elde edilmektedir. Bu çalışmada evrensel sabit bir gri değeri yerine renk kanalı ortalama değerleri kullanılmaktadır.

Kanal ortalama değerleri kullanılarak köşegen matris $M$ 'in elemanları şu şekilde hesaplanabilmektedir.

$$
\begin{aligned}
& \mathbf{M}=\left(\begin{array}{lll}
m_{11} & & \\
& m_{22} & \\
& & m_{33}
\end{array}\right) \\
& m_{11}=\frac{n u}{n c} \frac{\sum_{I_{c}} I_{k}^{c}}{\sum_{I_{u}} I_{k}^{u}} \\
& m_{22}=\frac{n u}{n c} \frac{\sum_{I_{c}}^{I_{y}^{c}}}{\sum_{I_{u}} I_{y}^{u}} \\
& m_{33}=\frac{n u}{n c} \frac{\sum_{I_{c}} I_{m}^{c}}{\sum_{I_{u}} I_{m}^{u}}
\end{aligned}
$$

burada $\mathbf{M}$ dönüşüm matrisini, $I$ (c,u sırasıyla bilinen ve bilinmeyen imgeler için alt ve üst indisler) imgeyi, $n_{(c, u)}$ sirasıyla $I_{(c, u)}$ daki toplam piksel sayısını, $I_{k}, I_{y}, I_{m}$ ise imgelerin farklı kanallarını (kırmızı, yeşil, mavi) belirtmektedir. Burada $\mathbf{M}$ in elemanları basit bir şekilde bilinen imge ile bilinmeyen imge arasındaki kanal ortalamaları oranları olarak hesaplanmaktadır. Bilinmeyen aydınlanma uzayından bilinen uzaya dönüştürme her piksel vektörünü $\mathbf{M}$ ile çarparak yapılabilmektedir.

$$
\hat{I}_{k y m}(x, y)=\mathbf{M} I_{k y m}(x, y)
$$

Buraya kadar olan ifadelerde genel bir imgenin imge ortalamaları kullanılarak gri dünya algoritması ile bir referansa göre dönüşümü açıklanmıştır. Daha önce belirtildiği gibi aydınlanmadan bağımsız tepkinin hesaplanması için, söz konusu olan imgelerde, plazmanın (doğal halde renksiz) ortalamas1 kullan1lırsa hücre sayısından doğrudan etkilenen imgenin genel ortalamasından daha verimli olacaktır. Ön planda bir çok kan hücresi yer almakta ve bunlarda aynı faktörlerden etkilenmekle beraber lekeleme işleminden plazmaya göre daha fazla etkilenmektedir. Bu koşullarda herhangi bir referans kullanmadan aydınlanmadan bağımsız piksel tepkisi doğrudan plazma ortalamasına bölünerek elde edilebilir. Ancak referans imgede bulunan renk karakteristiğine dönüșüm yapılmak istenildiğinde dönüşüm matrisin elemanlarının $\mathbf{M}$ hesaplanması gerekmektedir. Dönüşüm ve sonuçta düzgeleştirme, arka plan kendi ortalamasına bölünerek ve ön plan ortalamaları esas alınarak şu şekilde hesaplanmaktadır:

1. $I^{u}$ (giriş imgesi) piksel değerlerini arka plan $\left(I_{a}^{u}\right)$ ortalamasına bölerek aydınlanmadan bağımsız imgeyi $I^{v}$ hesapla. Aynı işlemin referans için daha önce yapıldı $\breve{g} 1$ kabul edilmiştir.

2. (3) eşitliğini ve maske $B^{\prime}$ yi kullanarak yeni ön planı $I_{o}^{v}$ hesapla.

3. Yeni ön plan ve referans ön plan ortalamasını kullanarak M dönüşüm matrisini hesapladıktan sonra (7) eşiliğini kullanarak $\hat{I_{o}^{v}}$ 'yu elde et.

4. Referansa göre dönüştürülmüş ön plan $\hat{I}_{o}^{v}$ piksellerini, $I^{v}$ deki değerleri ile yer değiştirerek $\hat{I}^{v}$ yi oluşturarak işlemi sonlandır.

Sonuçta giriş imgesi $I^{u}$ de (Şekil 1(a)) yer alan arka plan kendi ortalamasına bölünmüş (Şekil 3(a)), ön plan ise bu işleme ek olarak referans imge ön planı uzayına dönüştürülmüştür (Şekil 3(b)). Böylelikle aydınlanma ve belirlenen referansa (Şekil 3(d)) göre bir dïzgeleştirme gerçekleştirilmektedir (Şekil 3(c)). İşlem bir döngü içerisinde yinelendiğinde giriş imgesi ve referans ortalamaları oranı giderek 1 e yakınsayacağından kararlı bir duruma ulaşmaktadır.

\section{Deneysel Sonuçlar}

Önerilen yöntem, lekeleme zamanları şartları bilinmeyen, farklı zamanlarda farklı mikroskoplar ve kameralarla alınmış yaklaşı 200 imge üzerinde denenmiş ve genel olarak başar1lı bulunmuştur. Referans kümesinde toplam 10 imge kullanılmıştır. Bazı örnekler Şekil 4'te giriş ve sonuç imge ikilisi halinde gösterilmektedir. Bu imgeler genelde ön arka planlardan oluştuğu için yapmakta olduğumuz kabullere uymaktadır. Düzgeleştirme yönteminin çalışması için ön ve arka plan bölütlemesinin doğruluğu önemlidir. Bölütleme işleminde 


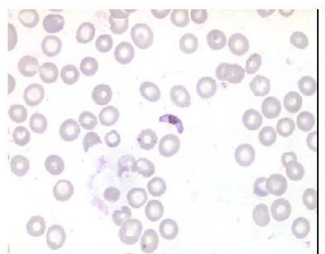

(a)

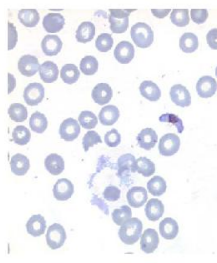

(c)

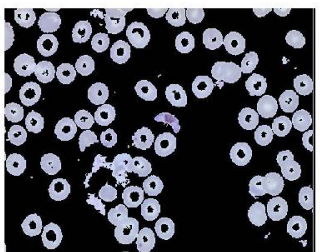

(b)

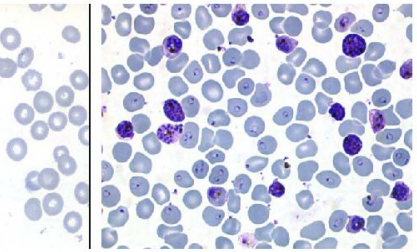

(d)
Şekil 3: Şekil 1(a) da gösterilen giriş imgesine ait (a) aydınlanmadan bağımsız imge $I^{v}$ (b) Ön planın referansa göre dönüşümü $\hat{I_{o}^{v}}$, (c) birleştirilmiş sonuç imgesi $\hat{I}^{v}$ (d) referans kümesinden bir imge.

kullanılan alan granulometrisine dayanan hücre alanı kestirimi, maske $B$ 'nin hesaplanması ve daha sonra ön ve arka plan ait sıklık dağılımlarının ayrılması global işlemlerdir. Bu nedenle bazı çok nadir homojen olmayan (imge içerisinde değişim gösteren aydınlanma vb durumlarda) imgelerde (Şekil $4(\mathrm{~g})$ sağ altta) arka plana ait bölgeler ön plan gibi işlem görmektedir. Ancak asıl hedefimiz olan sitma parazitleri hücrelere ve arka plana göre oldukça (lekeleme nedeniyle) koyu olduğundan tersi duruma rastlanmamıştır. Hücre sayısının çok az olduğı bir imgede ise alan granulometrisinden hücre alanı doğru kestirilemediğinden işlemlerin geri kalanı çalışamamıştır. Ancak bu tür durumlarda alan granulometrisi yerine bir sabit kullanılarak (imge kümesinden hesaplanabilecek bir ortalama hücre alanı) sonuç imgeye ulaşılabilir.

\section{Vargilar}

Bu çalışmada, Giemsa ile lekelenmiş kan hücre imgelerinin renk düzgelemesi için gri-dünya varsayımından uyarlanmış yeni bir yöntem sunulmuştur. Onerilen yöntemde, imge ilk önce ön ve arka plan olarak bölütlenmektedir. Daha sonra arka plan ortalamas1 kullanılarak aydınlanma etkileri giderilmekte ve ön plan imgesi bir referans kümesinde yer alan ön plan imge ortalamalarına göre düzgeleştirilmektedir. Gözle incelendiğinde, giriş imgesinin renk karakterinden bağımsız olarak, referans imgelerine yakın dönüşümü sağlanabildiği görülmektedir. Önerilen yöntem bir çok imge ïzerinde denenmiş ve başarılı bulunmuştur.

\section{Kaynakça}

[1] Jacqueline H. Carr and Bernadette Rodak, Clinical Hematology Atlas, W. B. Saunders, USA, 1998.

[2] Kobus Barnard, Practical colour constancy, Ph.d. thesis, Simon Fraser University School of Computing Science, 1999.
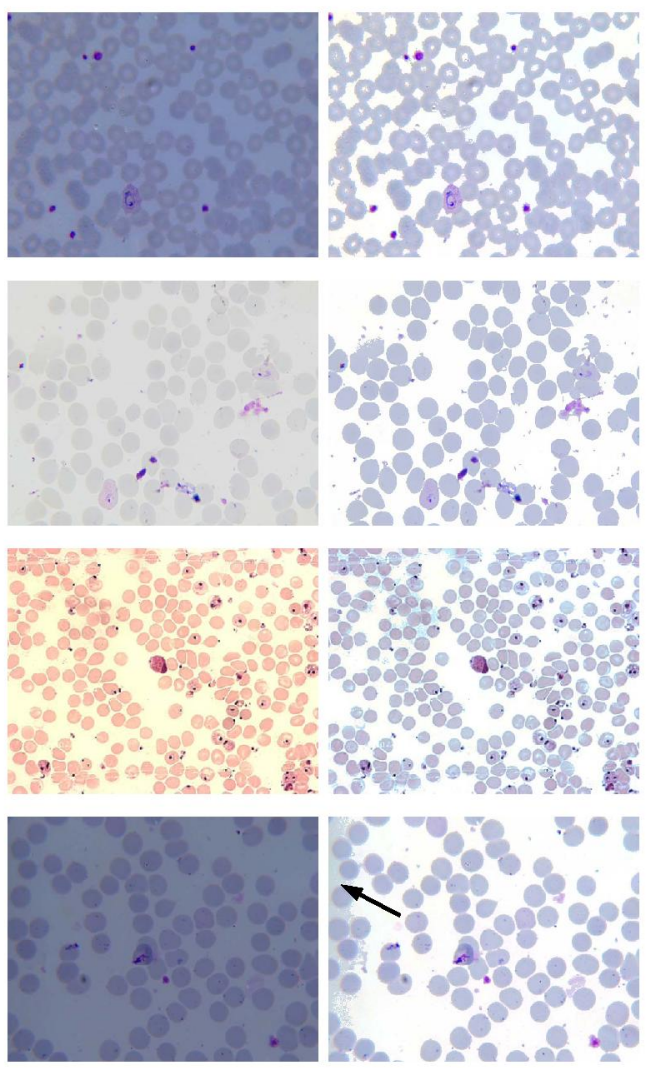

Şekil 4: (Sol kolon) Çeşitli giriş imgeleri için hesaplanmış sonuç imgeleri (Să̆ kolon).

[3] M. Vanrell, F. Lumbreras, A. Pujol, R. Baldrich, J. Llados, and J.J. Villanueva, "Colour normalisation based on background information," in Proceedings. 2001 International Conference on Image Processing, 2001, vol. 1, pp. 874-877.

[4] KNR M. Rao, Application of Mathematical Morphology to Biomedical Image Processing, Ph.D. thesis, U. Westminster, 2004.

[5] L. Vincent, "Granulometries and opening trees," Fundamenta Informaticae, vol. 41, pp. 57-90, 2000.

[6] P. Maragos, "Pattern spectrum and multiscale shape respresentation," IEEE Trans. PAMI., vol. 2, pp. 701-716, 1989.

[7] E.J. Breen and R. Jones, "Attribute openings, thinnings, and granulometries," CVIU, vol. 64, pp. 377-389, 1996.

[8] KNR M. Rao and A. Dempster, "Area-granulometry: an improved estimator of size distribution of image objects," Electronics Letters, vol. 37, pp. 50-951, 2001.

[9] F. Boray Tek, Andrew G. Dempster, and Izzet Kale, "Blood cell segmentation using minimum area watershed and circle radon transformations," in Proc. Int. Symp. on Mathematical Morphology, April 2005, vol. 1, pp. 739742.

[10] P. Soille, Morphological Image Analysis, Springer-Verlag, Heidelberg, 2003. 